\title{
An unusual Barothermometer
}

\author{
Dario Camuffo
}

National Research Council of Italy - Institute of Atmospheric Sciences and Climate, Corso Stati Uniti 4, 35127 Padua, Italy

Article history: received October 27, 2020; accepted December 17, 2020

\begin{abstract}
An unusual instrument, named "Barothermometer", belonging to the collection of Villa Vigoni, on the Como Lake, Italy, is analysed. The instrument is composed of a U-shaped thermoscope and a spirit thermometer. Both instruments have their tubes placed side-by-side on the same frame and use the same scale. It measures the air temperature and the tendency of the barometric pressure to predict weather changes. A study is made to clarify the operating principle and produce the instructions for use. The development of the ideas to which the instrument has been inspired follows a tree starting with the Galileo's thermoscope, the Amontons air thermometer and finally the Adie sympiesometer. The measuring method is typical of the first half of the $19^{\text {th }}$ century, but the construction details in aluminium, the fonts used in the printed instructions and the colour fading suggest that the instrument was built around 1930-40.
\end{abstract}

Keywords: Early meteorological instruments; History of science; Thermoscope; Barothermometer; Barometer; Thermometer.

\section{Introduction}

Villa Vigoni, on the Como Lake, Italy, is seat of workshops and cultural activities promoting the Italian-German relations within a European context, and preserves the original furnishing and decorations, left by the founder Heinrich Mylius (1769 - 1854) and later augmented by the Vigoni Family [Meda-Riquier et al., 2019]. The furniture is enriched by a library, paintings, statues and various pieces of art, and includes some technical devices, e.g. a small telescope, a watch aneroid barometer and an unusual instrument with name tag reporting the inscription «barotermometro» (i.e. barothermometer, in Italian) (Figure 1).

The name may suggest a similarity with other instruments, as follows.

(i) The traditional baro-thermometer is a combination of a barometer (e.g. J-shaped siphon barometer by Robert Hooke, or an aneroid capsule) and a metallic thermometer, or a Bourdon tube, mounted on the same frame (Figure 2a), often associated with hair hygrometer and clock. They could be produced separately and miniaturized watchsize (Figure 2b) to be carried in the pocket [Negretti and Zambra, 1864].

(ii) The air-baro-thermometer proposed by Schreiber [1875] consists of a balance barometer, an air thermometer to record the temperature of the external air, and an air thermometer to record the temperature of the recording instrument. The thermometers are composed of a tube, closed at the top and open below, filled with air, dipping into mercury, and balanced by a weight on a string passing over a pulley (Figure 2c).

(iii) The thermo-barometer, also called thermometrical barometer or hypsometer was invented by Wollaston [1817] and later improved by Regnault [1847]. It is a device to determine height measurements without a barometer. 


\section{Dario Camuffo}

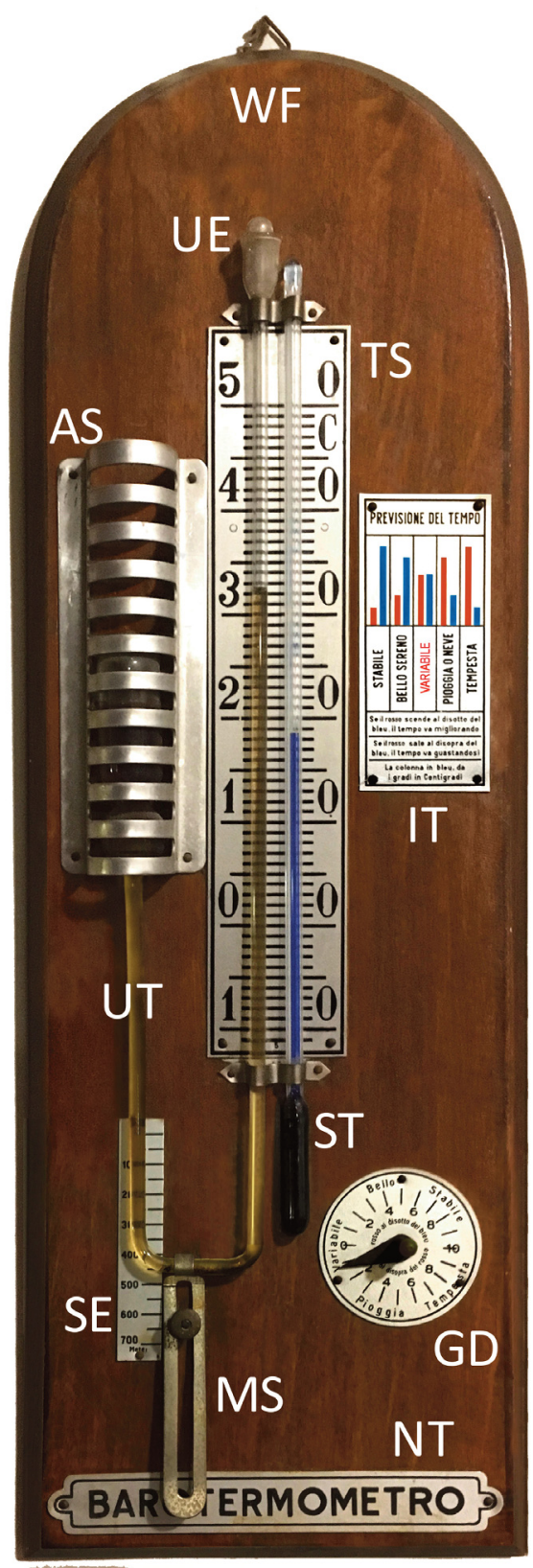

Figure 1. The Barothermometer (digitally restored) indicating $18.5^{\circ} \mathrm{C}$ and stormy weather. Letters to recognize the parts of which the instrument is composed (see text).

It consists of a thermometer with a narrow tube, through which the smallest temperature changes can be observed with resolution of a thousandth of a degree (Figure $2 \mathrm{~d}$ ). This thermometer is equipped with a pot of water heated to boiling with a spirit lamp. The thermometer is surrounded by the hot steam, and the boiling point of the water at the unknown altitude will be read with high accuracy. The physical principle is that liquids boil when their saturation vapour pressure equals the pressure exerted by the atmosphere on the free liquid surface, and the temperature at which this occurs is called boiling point. If the atmospheric pressure is lowered, e.g. climbing to higher altitudes above the sea level, lower saturation vapor pressures will be needed, and the boiling point will occur at lower temperatures. The boiling point at the higher elevation will be used as an input to the Clausius-Clapeyron equation to calculate the unknown altitude [Camuffo, 2019]. The thermo-barometer is essentially a thermometer, used to calculate a pressure and, therefore, a site elevation, and this explains the name [Negretti and Zambra, 1864]. 
The instrument in Villa Vigoni is none of the above-mentioned instruments. It is composed of a thermometer but does not include a traditional barometer, although it can detect pressure trends.

The aim of this paper is to recognize the measuring principle and the operation protocol of this particular instrument.



(a)

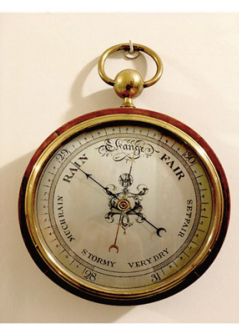

(b)

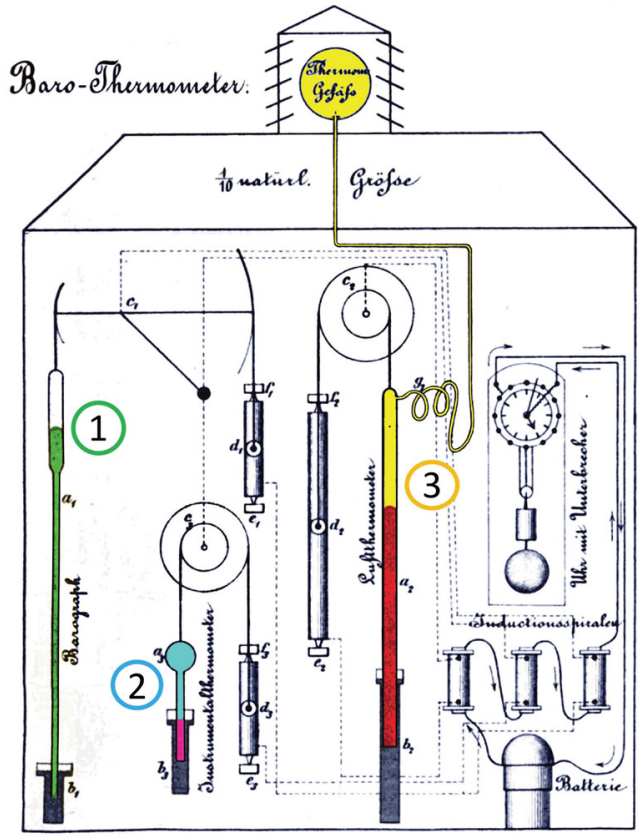

(c)

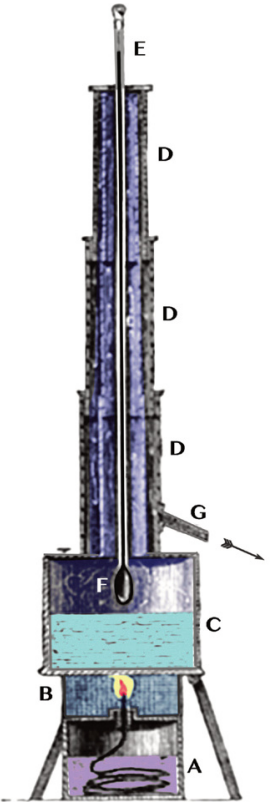

(d)

Figure 2. Selected barothermometers. (a) Household barometer and thermometer (from Ganot, 1860). (b) Watch-size aneroid barometer (Villa Vigoni collection). (c) Schreiber barothermometer including: (1) barometer (Barograph); (2) thermometer to record the temperature of the registering instrument (Instrumentalthermometer, cyan and pink); (3) air thermometer to record the temperature of the external air (Luftthermometer, yellow and red) with spherical bulb (Thermom Gefäß, yellow) located in the louvered screen on the roof of the case [from Schreiber, 1875]. (d) Wollaston thermo-barometer, also named boiling-point thermometer. A: reservoir of spirit to burn a flame in the volume B; C: reservoir of boiling water to produce steam in the upper volume $\mathrm{F}$ near the thermometer bulb and tube enclosed in the telescopic array D D D; E: emerging tube of the thermometer where readings are made; G: exhaust of steam and condensed water [from Negretti and Zambra, 1864].

\section{Description of the barothermometer}

\subsection{Parts of which the barothermometer is composed}

The barothermometer (Figure 1) of Villa Vigoni is handcrafted, without a logo or producer name. It is composed of

- a wooden frame (WF)

- a blue spirit-in-glass thermometer (ST);

- a U-shaped glass tube (UT) with an ampulla on the top of the left arm, while the right arm lies on the side of the thermometer tube. The upper end (UE) of the tube is shaped as a reversed bell with a spherical glass stopper on the top. The liquid inside is yellow, probably deriving from a discoloured red liquid.

- an aluminium shield (AS) to protect the ampulla from accidental bumps;

- a thermometric scale (TS) from -10 to $50^{\circ} \mathrm{C}$ located behind the two tubes;

- a mobile metal slit (MS) to adjust vertically the UT tube in correspondence of the elevation of the site. A black mark on the slit should be located at the corresponding elevation; 


\section{Dario Camuffo}

- an aluminium strip with indicated values from 0 to 700 . This refers to the elevation of the site (SE), expressed in $\mathrm{m}$ above mean sea level;

- a circular graduated dial (GD) with a hand-adjustable arrow fixed to a knob. There is an upper clockwise scale from 0 to 10, and a lower counter-clockwise scale also from 0 to 10. Units are not specified, and "+" or "-" signs are missing. To avoid confusion, in this context the upper scale will be indicated with positive values, and the lower with negative. The following headings (in Italian) are reported: -2 to $+2:$ «variable» (traditionally used in Italian barometers for «change»); +3 to +5 «fair»; +6 to +10 «stable» (traditionally used in Italian barometers for «very dry»); on the lower side: -3 to -6 «rain»; -6 to -10 «stormy». Some additional words give a friendly explanation. On the upper side: «red below the blue colour»; on the lower side: «blue above the red colour».

- an instruction table (IT) in aluminium, entitled «Weather Forecast» (Figure 3a). It reports examples of the weather classes deduced from the relative heights of two bars, coloured (faded) red and blue, with the following headings. Blue bar much higher than red: «stable»; blue bar higher than red: «fair - clear»; blue and red bars at the same level: «variable»; blue bar lower than red: «rain or snow»; blue bar much lower than red: «stormy». In the bottom, three notes, i.e. (i) «when the red bar falls below the blue, weather is getting better»; (ii) «when the red bar rises above the blue, weather is getting worse»; (iii) «the blue bar represents [temperature] in centigrade degrees».

- a name tag (NT) with written «barothermometer».

- an instruction paper sheet is glued on the back of the frame (Figure 4), with a few notes, as follows. Install the instrument far from heat sources. When the instrument is installed, remove the cork from the upper end of the tube and substitute it with the glass closure with spherical handle. Adjust the metal slit of the tube in correspondence of the elevation of the site. Take advantage of the instruction table and the circular graduated dial.

The used language indicates that the instrument was built in Italy. The colour fading occurred to the liquid in UT and the IT table (in Figure 1 the faded red colour has been digitally restored) indicates that the instrument is aged. The use of aluminium in various parts suggests a building date after 1930. The instruction sheet glued on the back has the title in Birch font that was created in 1879 but was popular in the first half of the $20^{\text {th }}$ century; the body uses a style that was very popular in Italy around 1930s-40s, i.e. typefaces sans serif inspired to Art Deco, e.g. capital G, M, N, P and R.

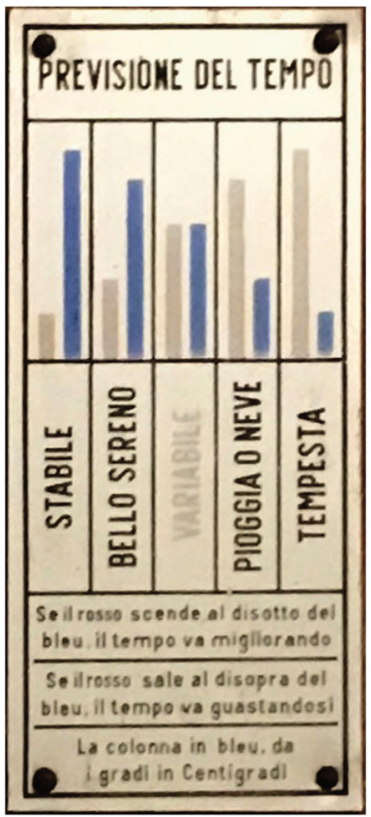

(a)

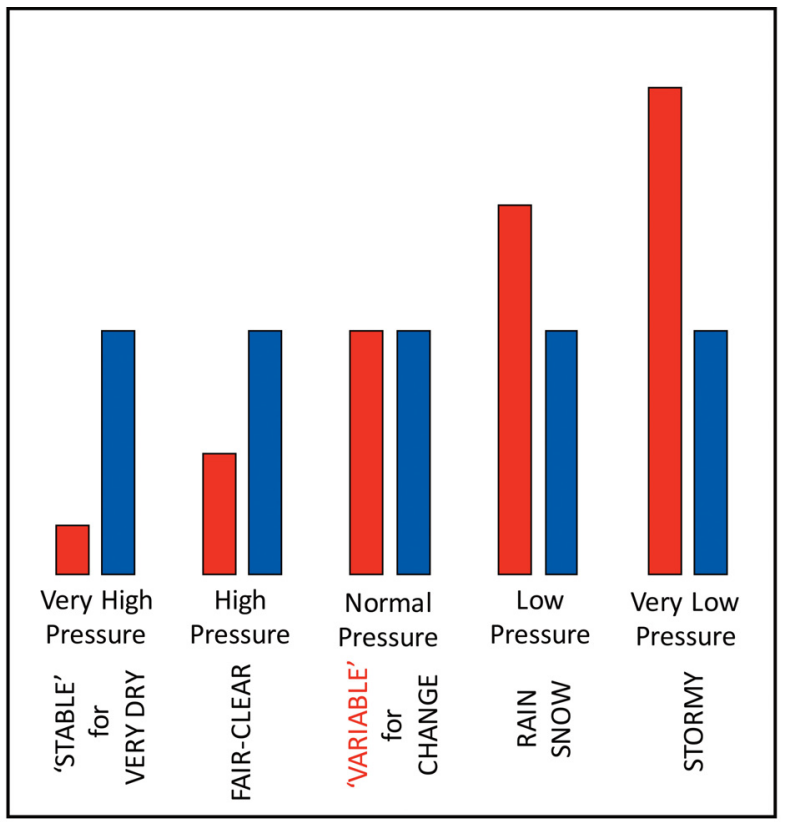

(b)

Figure 3. (a) The original instruction table (IT) where at each class the temperature (blue bar) is represented at different values from the highest to the lowest. This might be misleadingly interpreted from summer to winter. Red bars (now grey) represent the output of the UT tube. The red colour used in the bars and the heading «variable» has faded. (b) The same scheme, but redrawn making reference to temperature, always at the same level, to avoid misleading interpretation. 


\section{Istruzione per|'usodel Barolermomelro}

Togliere per prima cosa, il tappo di sughero e sostituirlo col tappo che porta il globetto di vetro.

Si deve poi regolare l'apparecchio secondo l'altezza in metri $s$ /mare del luogo ove viene collocato. Per fare questo occorre allentare la vite che serra il paletto (in basso a sinistra) e mettere il paletto, al segno - sul numero dei metricorrispondenti quindi avvitare nuovamente.

Non appendere l' istrumento al sole ed evitare la vicinanza di stufe od altre sorgenti di calore.

La Tabella: PREDIZIONI METEOROLOG/CHE, dà le necessarie spiegazioni, mentre il disco col bottone e lancetta serve a segnare lo stato precedente.

Figure 4. The paper sheet with instructions glued on the back of the frame.

\subsection{Operating principle of the Barothermometer}

A premise should be done about the limitations concerning the instrument inspection. In order to guarantee the safety of this vulnerable instrument, the study has been limited to photographic and visual analysis, avoiding any physical contact and making impossible the chemical analysis of the yellow liquid in UT, as well as the efficiency of the system to equalize the atmospheric pressure with the deliberate leakage around the ground glass stopper on the top of the tube (UE). However, this has not been essential to discover the physical principle on which the instrument is based.

From the above description, it is clear that the instrument is composed of a traditional spirit thermometer (ST) and an unknown device (i.e. UT) to measure the atmospheric pressure (Figure 5). This means that the UT glassware is in connection with the external air, and the part devoted to this aim is the upper end of the tube (UE), with a permanent small opening on the glass stopper, or a temporary one every time an observation is made.

A tube with permanent opening would require the use of non-volatile liquids, because the evaporation would cause a drift to the system. To this aim, the most popular liquids were mercury or oil. Mercury should be excluded for the yellow colour and transparency. Linseed oil is unlikely after the negative experience of the Newton linseed oil thermometer [Newton, 1701] because it sticks on the internal side of the capillary, making difficult or even impossible readings after a certain period of time [Camuffo and della Valle 2017]. Almond oil is the most likely candidate, and was used in the Adie [1819] sympiesometer. It leaves clean the interior of the glass tube, and may be coloured with a red dye (e.g. dragon blood dracena draco resin) but fades over time, even in indoor conditions, for the discolouring effect of light. As opposed, if a volatile liquid is used, e.g. wine-spirit, it is necessary to hinder evaporation with a hermetic glass stopper, and remove it for a very short time before an observation is made, to equalize the pressure. However, the glued sheet does not include this recommendation. In addition, it explains that the instrument had a cork for the transport, that had to be substituted with a glass stopper sent with the instrument. This implies that this stopper allows some leakage and the liquid is non-volatile, very likely almond oil. 


\section{Dario Camuffo}

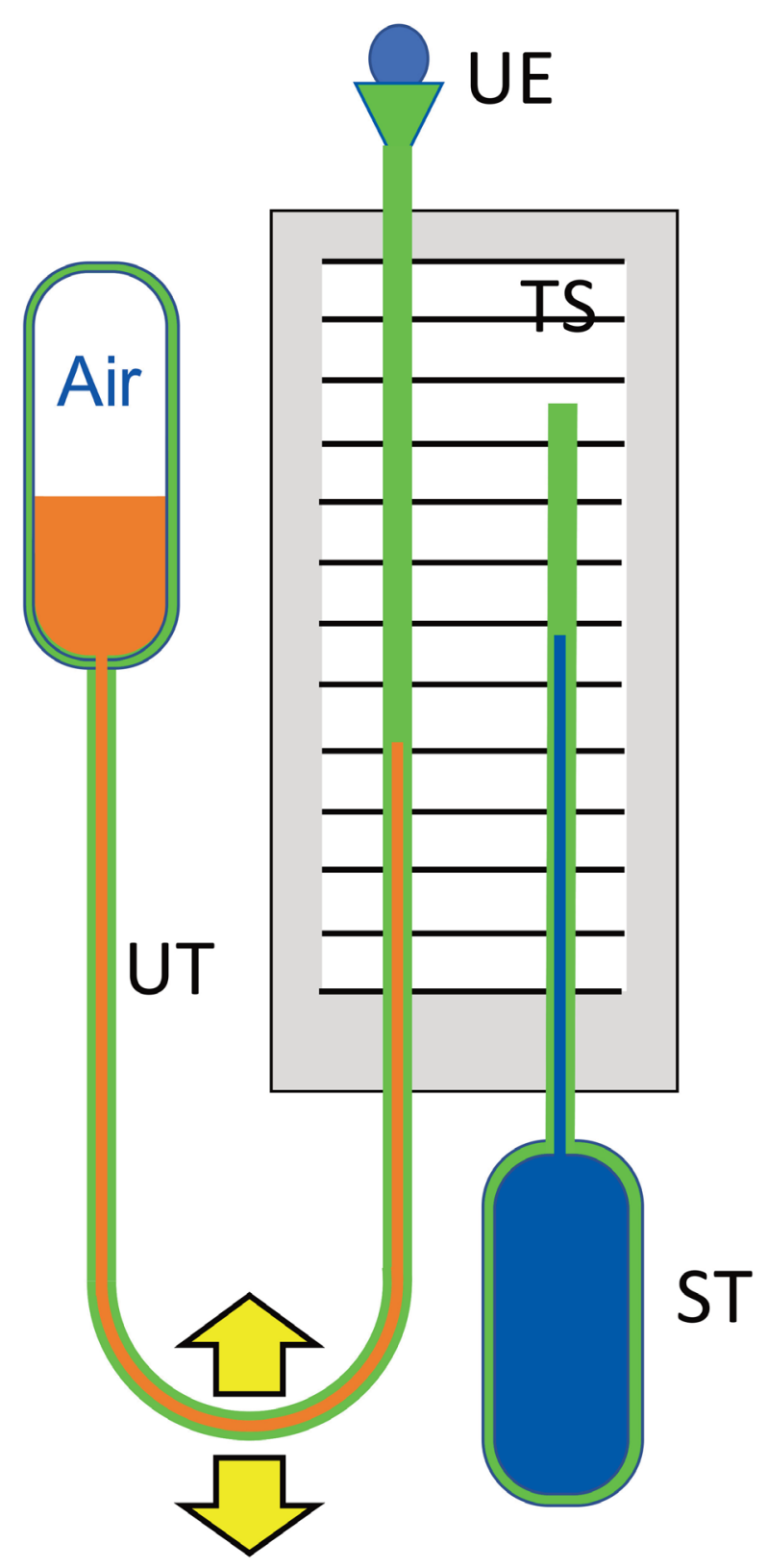

Figure 5. Scheme of the assembly constituted by the U-shaped device (UT) and the spirit thermometer (ST).

The ancestor of the UT device is the Galileo thermoscope (Figure 6a) built in 1593 [Middleton, 1966; Beaurepaire, 1994; 1995; Camuffo and Bertolin, 2012; Benicasa et al., 2019; Camuffo, 2019]. The thermoscope consisted of an ampulla with an air pocket and the pressure exerted by the air pocket moves the liquid column in the tube connected with the ampulla. The other end of the tube is open, to allow the free liquid motion, and is exposed to the atmospheric pressure. In the ampulla, the volume $(V)$ of the air pocket has a direct relationship with the air temperature $(T)$ and an opposite one with the atmospheric pressure $(P)$, i.e. $V$ will increase at increasing $T$ or decreasing $P$, and vice-versa. The thermoscope reading is given by the change $\Delta H$ of the height $H$ of the liquid column, which responds to changes in temperature $\Delta T$ and pressure $\Delta P$ according to the formula

$$
\Delta H=a_{1} \Delta T-a_{2} \Delta P
$$

where $a_{1}$ and $a_{2}$ are proportionality coefficients, characteristic of each individual instrument. 


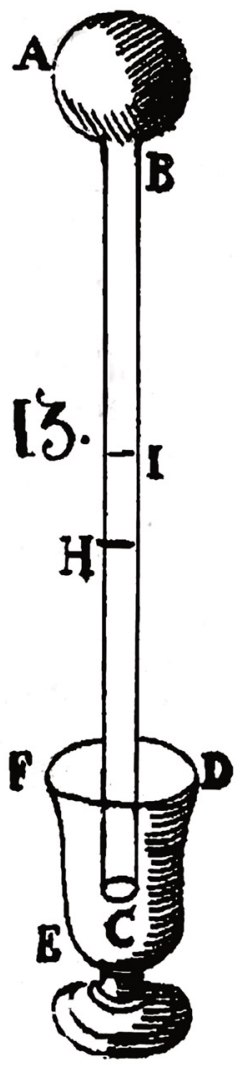

(a)

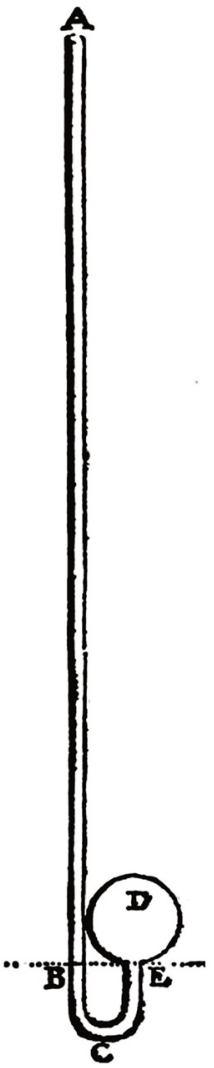

(b)

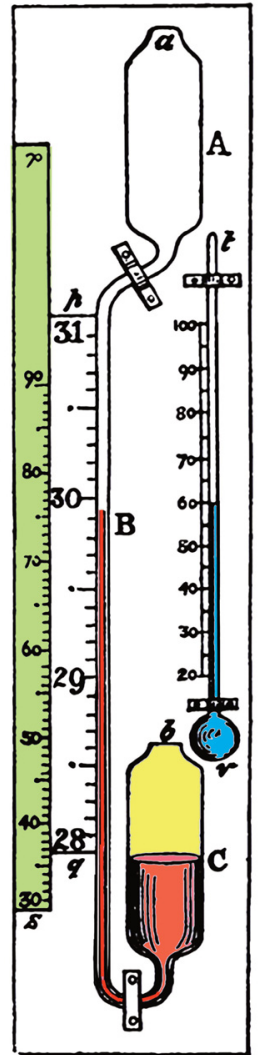

(c)

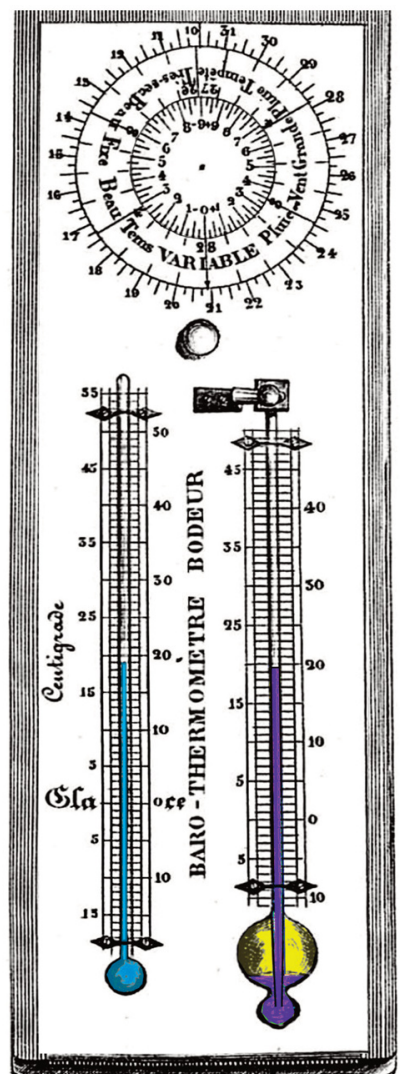

(d)

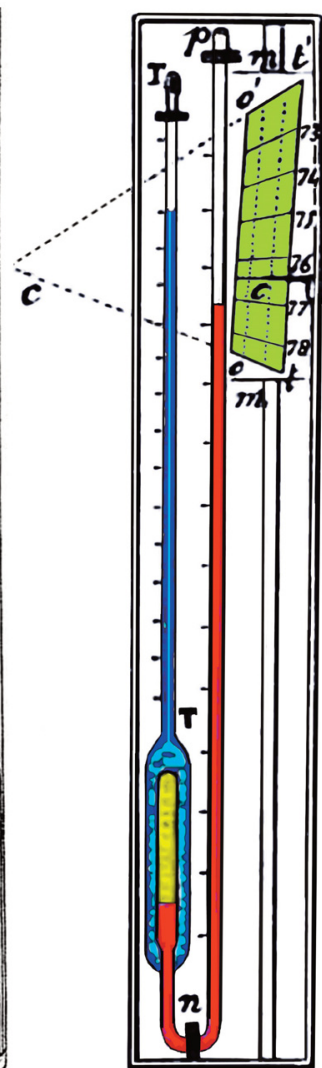

(e)

Figure 6. Instruments that may had inspired the barothermometer of Villa Vigoni. (a) Galileo thermoscope [from Borelli, 1670]; (b) Amontons thermometer (from Amontons, 1702); (c) Adie sympiesometer [from Adie, 1819]. In the figure, $\mathrm{ABC}$ is the thermoscope; $\mathrm{C}$ the phial including the hydrogen gas pocket (yellow) and the almond oil (red); $\mathrm{B}$ the tube. The upper volume A is open on the top $a$. On the left side, a rectangular graduated scale (green); on right side, a small thermometer (blue). (d) Bodeur baro-thermometer: thermometer (blue); thermoscope with the bulb filled of hydrogen (yellow), compressed by mercury (violet); top: circular scale [from Bodeur, 1838]; (e) Bunten sympiesometer [from Daguin, 1861], with rectangular graduated scale (green) to obtain pressure readings, from 73 to 78 Paris inch. The scale is opposite, i.e. it decreases at increasing pressure. Colour codes as in (c).

As the thermoscope is sensitive to both $T$ and $P$ variables, it behaves like a thermometer when $P$ is constant (i.e. $\Delta P=0$ ), and like a barometer when $T$ is constant (i.e. $\Delta T=0$ ). In general, however, both $T$ and $P$ are variable and the readings are difficult to interpret. The thermoscope was applied to a variety of uses, but with poor success, and was abandoned after the liquid-in-glass thermometer was invented in Florence in 1641 [Magalotti, 1666].

The thermoscope was improperly called air-thermometer, because the bulb was composed of an air pocket. However, the opposite end of the tube was open and the equilibrium level of the liquid column was determined by the combined effect of the air temperature and the atmospheric pressure. Therefore, it was also called thermo-baro-scope.

At the beginning of the $18^{\text {th }}$ century, Amontons [1702] found a solution to the problem of the twofold dependence of thermoscopes from $T$ and $P$. He built a thermoscope (Figure $6 \mathrm{~b}$ ) filled with mercury, with the same size of his barometer. Having clear in mind equation (1), he thought that the real $T$ could be obtained by summing the heights of two mercury columns read on the thermoscope $(\mathrm{H})$ and the barometer $(P)$, i.e.

$$
T=H+P .
$$




\section{Dario Camuffo}

The Amontons thermometer was popular in the first decades of the $18^{\text {th }}$ century. Later, it was abandoned for a number of problems connected with this instrument, e.g. the observer needed to have a thermometer and a barometer, and to sum the two readings; there was not a well defined scale; the thermometer was not linear; it could not be moved for spot measurements; the moisture in the air pocket could condense for the pressure and/or temperature [Camuffo and Jones, 2002; Camuffo et al., 2016]. In the 1730-1740 period, the Amontons thermometer was outclassed by the new liquid-in-glass thermometers produced by Fahrenheit [1724], Réaumur [1730] and Micheli $\mathrm{du}$ Crest [1741]. These were easier to handle, compact and light, precise, and gave directly the temperature readings in a well defined scale. A few exceptions existed, e.g. Giovanni Poleni in Padua, who in 1725 started a record with an Amontons thermometer and continued to use the same instrument till the end of his life, in 1761, to keep homogeneous the record [Camuffo and Jones, 2002].

An opposite approach was the sympiesometer (Figure 6c) invented by Adie [1819], i.e. a marine barometer inspired by the Amontons thermometer, but finalized to obtain $P$ instead of $T$. Amontons used a thermoscope and corrected for $P$; Adie used the same methodology, but corrected for $T$. The sympiesometer is the combination of a thermoscope and a thermometer. This thermoscope had a complex construction to be adapted to the marine use and smooth the adverse effects of yaw, pitch and roll of the ship. Adie used a phial with hydrogen instead of air and almond oil instead of mercury to increase the viscous friction and reduce the free oscillations of the liquid. A free volume is located on the upper end of the tube to act as a reservoir and keep the liquid in case of violent oscillations or tropical temperatures. This volume has a hole on the top, to allow pressure equalization. The instrument responded to both $T$ and $P$, and the unwanted $T$ contribution was removed using a traditional mercury thermometer that was fixed to the same frame.

The baro-thermometer patented by Bodeur [1838] (Figure 6d) is similar to the Adie sympiesometer, equally based on the comparison of the readings taken on a thermoscope and a thermometer. Two differences may be found. Instead of the linear scale, it has a circular graduated dial to calculate the pressure changes and recognize the weather types. Instead of almond oil, mercury was used. In the next two decades, Bunten ${ }^{1}$ [Alluard, 1847; Pionnier, 1844; Pouillet, 1856] (Figure 6e), Silbermann and Gaudin [Daguin, 1861] built other very similar instruments, with some minor changes to improve the scale readability.

The Villa Vigoni barothermometer includes a thermoscope and a thermometer, and its aim is the same as the sympiesometer by Adie, Bodeur, Bunten, Silbermann and Gaudin, but simplified. The scale of the thermoscope is neither mobile, not calibrated. It cannot obtain accurate barometric values. It is only aimed to point out general pressure tendencies, i.e. increasing pressure and fine weather or falling pressure and bad weather. Possibly, the Italian manufacturer was inspired by the description reported by Pagliani [1891], with text and drawing close to Daguin [1861], but written in Italian.

An overview of the operating principles and key features of the above instruments are summarized in Table 1

\begin{tabular}{cccc} 
Instrument & Invention Date & Composed of & $\begin{array}{c}\text { Functional dependence } \\
\text { \& final result }\end{array}$ \\
Galileo thermoscope & 1593 & thermoscope & $T-P$ \\
\hline Amontons thermometer & 1702 & $\begin{array}{c}\text { thermoscope \& } \\
\text { barometer }\end{array}$ & $(T-P)+P=T$ \\
\hline Adie sympiesometer & 1819 & $\begin{array}{c}\text { thermoscope \& } \\
\text { thermometer }\end{array}$ & $(T-P)-T=-P$ \\
\hline $\begin{array}{c}\text { Bodeur, Bunten, Silbermann } \\
\text { and Gaudin }\end{array}$ & $1840-60$ & $\begin{array}{c}\text { thermoscope \& } \\
\text { thermometer }\end{array}$ & $(T-P)-T=-P$ \\
\hline Vigoni barothermometer & $1930-40 ?$ & $\begin{array}{c}\text { thermoscope \& } \\
\text { thermometer }\end{array}$ & $(T-P) \& T$ \\
\hline
\end{tabular}

Table 1. Family tree of the instruments that have inspired the barothermometer of Villa Vigoni and comparison with it.

\footnotetext{
${ }^{1}$ Sometimes misprinted Bunsen, e.g. Daguin [1861]. M. Bodeur and M. Bunten were instrument makers, living in Paris. The former at Passage Dauphine 36, the latter Quai Pelletier, 26. Their names remain unknown, because they were always indicated M. i.e. Mister (Monsieur in French).
} 


\subsection{Operating protocol}

The instrument is not provided of a detailed instruction manual. However, an operating protocol may be drafted after the knowledge of the physical mechanisms involved, as follows.

Once installed, the instrument shall be set to the appropriate elevation above the mean sea level acting on the mobile metal slit (MS). The black line shall be positioned on the line correspondent to the site elevation (SE) reported on the graduated strip. This operation constitutes the initial setting to counterbalance the effect of the site elevation.

The temperature is given by the spirit thermometer (ST), and the actual temperature in Celsius can be read on the thermometric scale (TC) from the level of the blue liquid column.

The atmospheric pressure is given by the red liquid column (now yellow after fading). However, the actual $\mathrm{P}$ value is not precisely determined. It is in some way qualitatively represented on the common temperature scale (TC), but without reference between pressure unit (e.g. inch, $\mathrm{mm} \mathrm{Hg}$, torr, mbar, $\mathrm{hPa}$,) and the indicated figures in ${ }^{\circ} \mathrm{C}$.

The circular graduated dial (GD) is helpful to compare the situation of the previous reading and see how much the pressure has changed, and will serve as a reference for the next reading. The printed comments act as a Weather Wisdom, i.e. they help to predict weather changes that are likely to occur, e.g. if weather is improving or worsening, and some typical conditions that might be expected, e.g. sunshine, rain, storms.

The instruction table (IT) helps to interpret readings after the comparison of the red and blue bars that represent the relationships between the red and blue liquid columns. The heights of the two bars should be interpreted qualitatively, in a relative way. The key factor is which of the two is higher, and if the difference is small, medium, large, positive or negative. Although the IT scheme is relatively correct, the fact that the blue bar is shown very high in the first class (i.e. «stable») and very low in the last one (i.e. «stormy») is misleading because one might interpret that «stable» occurs only in winter when $T$ is lowest as in the IT scheme, and «stormy» in summer when $T$ is highest. As opposed, the occurrence of these classes is independent of the absolute level of the blue bar, but only depends on the relative position of the red and blue levels. It would be better to redraw it (Figure 3b), keeping the blue reference bar (that represents $T$ ) always as the same neutral level, and look at the relative position of the red bar (that represents $T-P$ ) when the atmospheric pressure is very high, high, normal, low or very low. It must be reminded that $T$ and $\mathrm{P}$ have an opposite dependence, i.e. a pressure increase produces a decrease of the red bar. Therefore, when pressure is high, the red bar is lower than the blue one, and vice-versa.

\section{Conclusions}

The unusual barothermometer of Villa Vigoni constitutes an interesting piece in the history of science. It is a unique weather instrument for household purposes that gives the temperature and the pressure tendency useful to predict weather changes. In this paper, it has been theoretically analysed. Its operating principle and use have been clarified.

The methodology on which the instrument is based refers to an initial idea of the $18^{\text {th }}$ century, i.e. the Amontons thermometer and the subsequent developments of the first half of the $19^{\text {th }}$ century, i.e. the sympiesometer by Adie further developed by Bodeur, Bunten, Silbermann and Gaudin. The sympiesometer was particularly appreciated for marine use.

However, the language, the use of aluminium, the typographic fonts and the colour fading suggest that this device was built in Italy around 1930-40. Therefore, it seems to belong to the successive acquisition that the Vigoni Family added to the original collection of Heinrich Mylius. It is surprising that an instrument, based on such an early methodology, was built in the $20^{\text {th }}$ century.

Acknowledgements. The instrument was observed and photographed by the author when he attended the Scientific Symposium «Cultural heritage in crisis: Challenges in times of climate change and digitalisation» held in Villa Vigoni, 27 29 November 2019. Sincere thanks are due to the Secretary General of Villa Vigoni, Dr. Christiane Liermann Traniello, Dr Giovanni Meda Riquier and the whole Staff for the wonderful hospitality during the Symposium, and for having kindly permitted and favoured this publication, providing useful information about the instrument. The author is grateful to the Referees for their appreciation and useful suggestions. 


\section{Dario Camuffo}

\section{References}

Adie A. (1819). Specification of the patent granted to Alexander Adie, of Edinburgh, optician, for an improvement of the air barometer, which improved instrument is to be called sympiesometer, Repert. Arts, 2nd Ser., 35, 257-265.

Alluard E. (1847). Du baromètre considéré comme instrument de nivellement, du sympiézomètre et du thermomètre barométrique, Bulletin du Musée de l'industrie, 12, 145-156.

Amontons G. (1702). Discours sur quelques propriétés de l'Air \& le moyen d'en connoître la température dans tous les climats de la Terre, Mémoires de Mathématique et de Physique, Martin Coignard \& Guerin, Paris, 155-174.

Beaurepaire M. (1994). L'observation thermique de l'atmosphère en France et dans les pays proches aux dix-septième et dix-huitième siècles: L'invention du thermomètre. Le traitement des données anciennes, Histoire de la Physique, Université Paris-Sorbonne - Paris IV, Paris. https://tel.archives-ouvertes.fr/tel-00962194

Beaurepaire M. (1995). L'invention du thermomètre, La Météorologie, 8 série, 95-100. Doi:10.4267/2042/52032.

Benincasa F., M. De Vincenzi, G. Fasano (2019). Storia della strumentazione meteorologica nella cultura occidentale. CNR Istituto di Biometeorologia, Florence, http://eprints.bice.rm.cnr.it/18878/.

Bodeur ? (1838). Deux instruments propres à mesurer la pression atmosphérique, et dont les dimensions sont assez petites pour le render très portatifs. Séance du 18 Juin 1838. Bull. Soc. Geol. France, 9, 342-345.

Camuffo D. (2019). Microclimate for cultural heritage - Measurement, risk assessment, conservation, restoration and maintenance of indoor and outdoor monuments, Third Edition, Elsevier, Amsterdam. ISBN 978-0-444-641069.

Camuffo D., C. Bertolin (2012a). The earliest temperature observations in the world: the Medici Network (16541670), Clim. Chang., 111, 335-363, doi:10.1007/s10584-009-9649-4.

Camuffo D., A. della Valle (2017). The Newton linseed oil thermometer: an evaluation of its departure from linearity, Weather, 72, (3), 84-85, doi:10.1002/wea.2909.

Camuffo D., A. della Valle, C. Bertolin, E. Santorelli (2016). The Stancari air thermometer and the 1715-1737 record in Bologna, Italy, Clim. Chang., 139, 623-636, doi:10.1007/s10584-016-1797-8.

Camuffo D., P. Jones (2002). Improved understanding of past climatic variability from early daily European instrumental sources, Kluwer, Dordrecht, doi:10.1023/A:1014902904197.

Daguin P.A. (1861) Traité élémentaire de physique théorique et expérimentale, 1, Bonal \& Gibrac, Toulouse.

du Crest J-B.M. (1741). Description de la méthode d'un thermomètre universel, Valleyre, Paris

Fahrenheit D.G. (1724). Experimenta circa gradum caloris liquorum non- nullorum ebullentium instituta, Philos. Trans. R. Soc., 381 (23), 1-3.

Ganot A. (1860). Traité de physique expérimentale et appliquée, et de météorologie. Auteur-éditeur, Paris.

Magalotti L. (1666). Saggi di naturali esperienze fatte nell’Accademia del Cimento, Cocchini, Florence.

Meda-Riquier G., V. Usselmann, C. Liermann-Traniello (2019). Enrico Mylius 1769-1854. Una biografia, Villa Vigoni Editore/Verlag, Loveno di Menaggio, ISBN 9788890817991.

Middleton W.E.K. (1966). A history of the thermometer and its use in meteorology. Hopkins Press, Baltimore, doi:10.1002/qj.49709440024.

Negretti E., J.W. Zambra (1864). Meteorological instruments: explanatory of their scientific principles, method of construction, and practical utility, Negretti \& Zambra Establishments, London.

Newton I. (1701). Scala graduum caloris: calorum descriptiones et signa. Philos. Trans. R. Soc., 22: 824- 829.

Pagliani S. (1891). Supplemento alla sesta edizione della Enciclopedia Italiana, 2. Unione Tipografico Editrice, Torino, 165.

Pionnier C. (1844). De l'esprit industriel, Rev. Scient. et Indust. Par., 17, 364-366.

Pouillet C. (1856) Eléments de Physique expérimentale et de Météorologie, Hacette, Paris.

Reaumur alias R.A. de Ferchaud (1730). Règles pour construire des thermomètres dont les degrés soient comparables et qui donnent des idées d'un chaud et d'un froid qui puissent être rapportés à des mesures connues, Mem. Acad. R. Sci. Paris, 452-457.

Regnault H.V. (1847). Cours élémentaire de chimie, Masson, Paris.

Schreiber P. (1875). Theorie eines neuen registerenden Luft-Thermometers. Carls Rep., 11, 1-41.

Wollaston F.J.H. (1817). Description of a thermometrical barometer for measuring altitudes, Philos. Trans. R. Soc., 107, 183-196, doi:10.1098/rstl.1817.0014. 
An unusual Barothermometer

*CORRESPONDING AUTHOR: Dario CAMUFFO,

National Research Council

Institute of Atmospheric Sciences and Climate, Padua, Italy e-mail: d.camuffo@isac.cnr.it (c) 2021 the Istituto Nazionale di Geofisica e Vulcanologia. 